\section{Reference base}
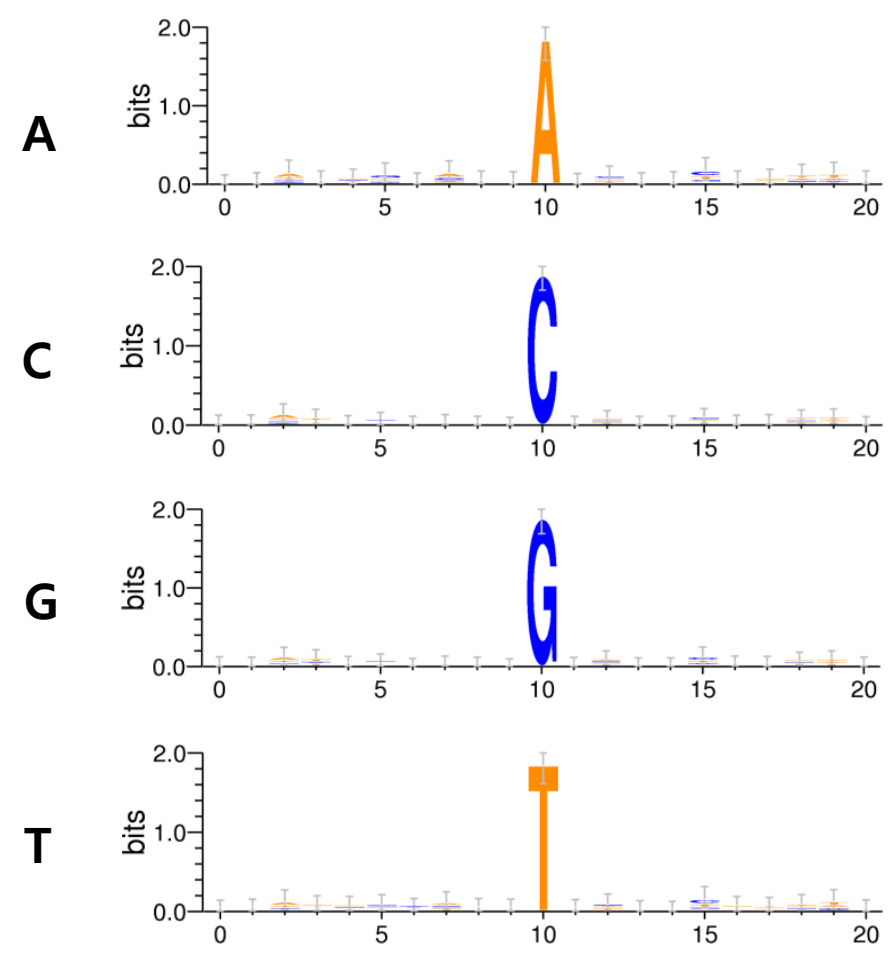

Mutated base
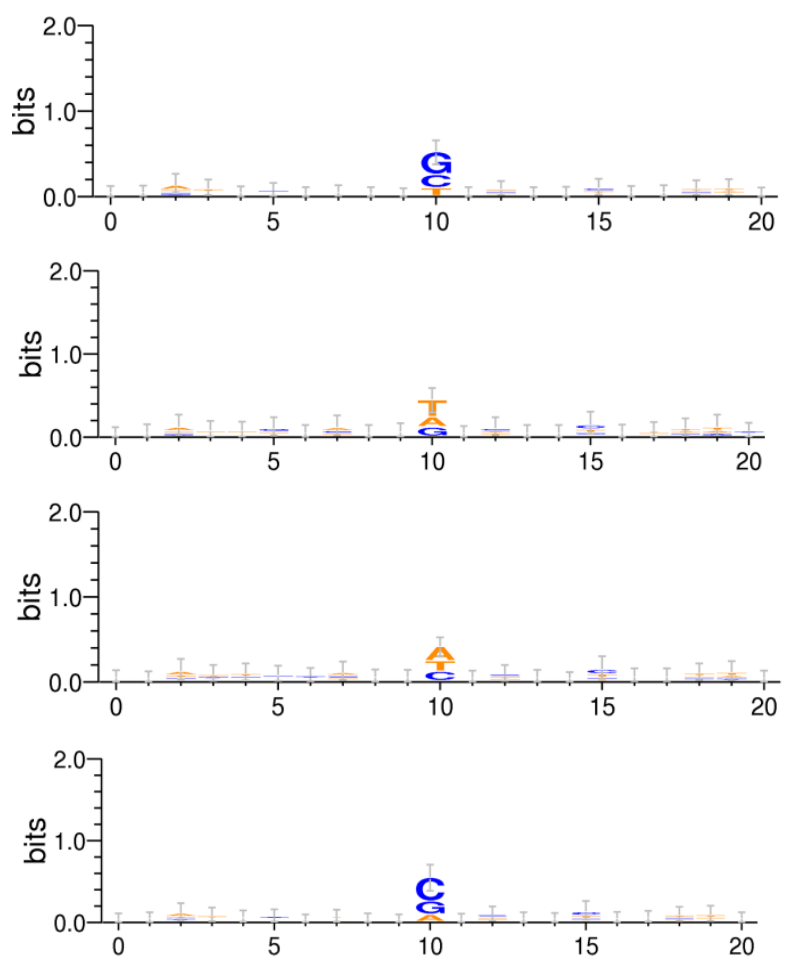

Figure. S3. Probability of the flanking sequences of the tumor-specific mutation sites Positional probability of the flanking sequences of the each of the reference and the mutated nucleotide base of the tumor-specific mutations are plotted by using Weblogo software. 